\title{
Corrective Primary Impression Technique
}

\author{
Aquaviva Fernandes ${ }^{1, *}$, Neha Dua ${ }^{1}$ and Manisha Herekar ${ }^{2}$ \\ ${ }^{1}$ Department of Prosthodontics, KLE VK Institute of Dental Sciences, Nehru Nagar, Belgaum - 590010, Karnataka (In- \\ dia) \\ ${ }_{2}^{2}$ Maratha Mandal Dental College, Belgaum, Consultant, Dental Specialty Clinic \& Implant Center, Tilakwadi, Belgaum \\ - 590006, Karnataka (India)
}

\begin{abstract}
The article describes a simple, quick and corrective technique for making the preliminary impression. It records the extensions better as compared to the impressions made using only impression compound. This technique is accurate and gives properly extended custom tray. Any deficiencies seen in the compound primary impression are corrected using this technique hence, this technique is called as a "corrective primary impression technique".
\end{abstract}

Failure to use an accurately extended custom tray for making final impression eliminates the necessary information regarding the anatomy of the basal seats available for the dentures [1-5]. For the fabrication of an accurate custom tray a correctly recorded preliminary impression plays an important role.

The objectives of the primary impression are to record all the areas to be covered by the intaglio surface of the dentures and the adjacent landmarks with an impression material which is accurate and incorporates the minimum tissue displacement [5].

Several authors [1-4] advocate different types of preliminary impression techniques. Some have suggested the use of alginate in an oversized perforated tray, where as others recommended use of impression compound by using a stock tray [2-4]. Boucher recommended the use of compound tray for border molding procedure [2].

This article presents a simple, quick, and reliable technique to make preliminary impression for edentulous patients.

\section{PROCEDURE}

1. Select a stock tray for the maxillary and mandibular edentulous ridges.

2. Soften the impression compound (Y- Dents, Delhi, India) in the hot water bath of $43^{\circ} \mathrm{C}$ and knead it.

3. Load the stock tray with softened and kneaded impression compound (Y- Dents, Delhi, India), then orient and seat the stock tray into the patient's mouth.

4. Ask the patient to perform physiologic movements to record the borders in the impression or a manual manipulation can also be performed by pulling the cheeks of the patients in an outward, downward, inward direction.

Address correspondence to this author at the Department of Prosthodontics, KLE VK Institute of Dental Sciences, Nehru Nagar, Belgaum - 590010, Karnataka (India); Tel: +91-9822124127;

E-mail: fernandesdent27@yahoo.com
5. Before the impression is set, move the impression away from the tissues in the patient's mouth. This causes displacement of the compound away from the tissues and creating space for alginate.

6. Care should be taken that the displacement is within the limits to create the space.

7. Remove the impression from the patient's mouth, examine the impression for extensions.

8. Place the impression back into the patient's mouth and check the extensions.

9. Take out the impression from patient's mouth and roughen the impression surface by making grooves. This will enable mechanical retention of alginate (Fig. 1). Extending the grooves upto the borders of compound impression will allow the alginate material to pass through.

10. Following which apply alginate adhesive. The application of adhesive will reinforce the retention of alginate especially that the thickness of alginate is not sufficient to hold on its own.

11. Now, mix the irreversible hydrocolloid (Tropicalgin, Roviogo, Italy) according to the manufacturers specifications and load the primary impression compound tray, within the confine of the compound impression.

12. Just before inserting the impression material, instruct the patients to gargle their mouth with astringent mouthwash to reduce the viscosity of the saliva. Place the tray to the patient's mouth and perform the manual manipulation of the borders.

13. Remove the impression tray from the patient's mouth after the alginate is set. Now, examine the impression for the overextended borders.

14. An overextended area will expose the impression compound, this area should be marked using an indelible pencil which will transferred primary cast and can be relieved in the custom tray later (Fig. 2). 


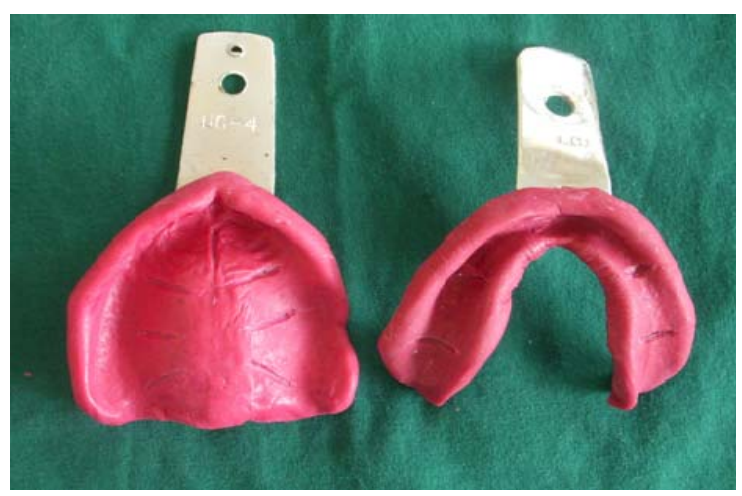

Fig. (1). Primary impression with retentive grooves.

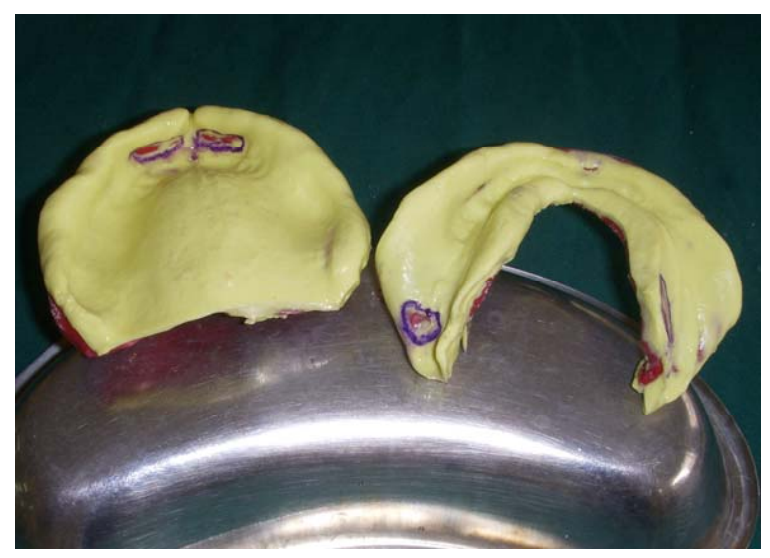

Fig. (2). Corrective primary impression with alginate, showing well recorded borders and exposed compound marked in indebile pencil.

15. The cast should be poured within 12 minutes after the impression making to prevent the distortion of the alginate impression material.

\section{ADVANTAGES}

1. The technique described is quick, simple and reliable.
2. The impression compound provides scaffolding and a better support for the alginate impression material, which alginate does not provide on its own.

3. It is noted that the under extended borders in the impression compound are corrected in the alginate impression hence it can also be called as "corrective primary impression technique".

4. This technique does not provide any gross over extension however, the over extended areas of the compound impression can be identified, marked and corrected in the custom tray.

5. The use of alginate in the technique does not displace the tissues in the border areas grossly as the impression compound does.

6. The impression obtained by this technique records details and is more accurate hence, it provides a stable and properly extended better close fitting custom tray.

\section{SUMMARY AND CONCLUSION}

The article describes a simple, quick and corrective technique for making the preliminary impression. The defects, which are met in the primary impression with compound, can be corrected with the use of alginate hence this technique can be called as "corrective primary impression technique". As this is a new technique, its usefulness and relevance needs to be evaluated further.

\section{REFERENCES}

[1] Boucher CO. Complete denture prosthodontics : the state of the art. Prosthet Dent 2004; 92: 309-15.

[2] Boucher's. Prosthodontic treatment for edentulous patients. $9^{\text {th }}$ ed. Louis.Toronto. Princeton: The CV Mosby St 1985; pp.152-5.

[3] Sharry JJ. Complete denture prosthodontics. $3^{\text {rd }}$ ed. Blakiston: McGraw Hill 1974.

[4] Heartwell CM. Textbook of complete dentures. $5^{\text {th }}$ ed. London: Lea \& Febiger.Philadelphia 1993; pp. 232-5.

[5] Carlsson GE. Facts and Fallacies : an evidence base for complete dentures. Dent Update 2006; 33:134-42.

(C) Fernandes et al.; Licensee Bentham Open.

This is an open access article licensed under the terms of the Creative Commons Attribution Non-Commercial License (http://creativecommons.org/licenses/by-nc/3.0/) which permits unrestricted, non-commercial use, distribution and reproduction in any medium, provided the work is properly cited. 